\title{
População em vulnerabilidade, intersetorialidade e cidadania: articulando saberes e ações
}

Population in vulnerability, inter-sector cooperation and citizenship: interconnecting knowledge and actions

\author{
Regina Célia Fiorati \\ Doutora e Docente da Faculdade de Medicina de Ribeirão Preto da \\ Universidade de São Paulo. \\ E-mail: reginacf@fmrp.usp.br

\section{Regina Yoneko Dakuzaku Carretta} \\ Doutora e Docente da Faculdade de Medicina de Ribeirão Preto da \\ Universidade de São Paulo. \\ E-mail: reginadcœfmrp.usp.br

\section{Maria Paula Panúncio-Pinto} \\ Doutora e Docente da Faculdade de Medicina de Ribeirão Preto da \\ Universidade de São Paulo. \\ E-mail: mapaulaœfmrp.usp.br

\section{Beatriz Cardoso Lobato} \\ Terapeuta Ocupacional. Mestre, Técnica-Especialista de Labora- \\ tório do Curso TO FRMRP-USP. \\ E-mail: beatriz@fmrp.usp.br

\section{Leonardo Martins Kebbe} \\ Doutor e Docente da Faculdade de Medicina de Ribeirão Preto da \\ Universidade de São Paulo. \\ E-mail: kebbeळfmrp.usp.br

\section{Correspondência} \\ Regina Célia Fiorati \\ Av Bandeirantes, 3900, Bairro Monte Alegre, CEP 14049-900, Ri- \\ beirão Preto, SP, Brasil.
}

\section{Resumo}

Este artigo apresenta relato referente ao "I Encontro Saúde Ocupação e Contextos Psicossociais: populações em vulnerabilidade, intersetorialidade e cidadania”, realizado em agosto de 2012 pelo curso de Terapia Ocupacional da Faculdade de Medicina de Ribeirão Preto - Universidade de São Paulo. Os objetivos do evento foram discutir as múltiplas causalidades e a complexidade envolvida no fenômeno do crescimento da população em situação de rua na conjuntura geral do país e do mundo e no contexto do município; iniciar uma análise e caracterização social dessa população; e elaborar estratégias para elaboração de políticas públicas de inclusão social, redução de iniquidades e desigualdades e erradicação da pobreza no município de Ribeirão Preto, na interface entre as dimensões de atuação, recursos e responsabilidades de vários setores da administração pública no município (saúde, educação, cultura, habitação, transportes e meio ambiente, entre outros) e organizações da sociedade civil. 0 evento gerou documento com propostas de estratégias voltadas à atenção a pessoas em situação de rua, que foi entregue à Prefeitura, à Câmara de Vereadores, ao Ministério Público e a representantes de movimentos sociais. É possível concluir que o encontro promoveu uma importante articulação para subsidiar a formação de fóruns intersetoriais e desencadear ações voltadas à atenção à população em vulnerabilidade social.

Palavras-chave: Vulnerabilidade Social; Políticas Públicas; Intersetorialidade; Cidadania; Terapia Ocupacional Social. 


\section{Abstract}

This article presents a critical report regarding the " $1^{\text {st }}$ Meeting Occupational Health and Psychosocial Contexts: populations in vulnerability, inter-sector cooperation, and citizenship", held in August 2012 by the Occupational Therapy course of the School of Medicine of Ribeirão Preto - University of São Paulo. This event aimed to discuss the multiple causes and the complexity involved in the phenomenon of the increasing population undergoing homeless conditions in the general country conjuncture and in the municipal context; initiate an analysis and social characterization of this population; and devise strategies to create public policies for social inclusion, reduction of inequalities, and eradication of poverty in the city of Ribeirão Preto, São Paulo, Brazil, in an interface between the dimensions of action, resources, and responsibilities of many sectors of the public administration in the city (health, education, culture, housing, transportation, and environment, among others) and civil society organizations. The event has generated a document with proposals for strategies aimed at providing homeless people with assistance, which was delivered to the City Hall, the City Council, the Public Prosecutor's Office, and representatives of social movements. It may be concluded that the meeting has promoted an important interconnection to provide means to the creation of inter-sector cooperation forums and trigger actions aimed at assisting the population in social vulnerability.

Keywords: Social Vulnerability; Public Policies; Inter-Sector Cooperation; Citizenship; Social Occupational Therapy.

\section{Introdução}

O fenômeno de pessoas em situação de rua pode ser observado em diversos países do mundo. Ele é polissêmico e decorre de um processo de múltiplas determinações, como as crises econômicas, a precarização das relações e condições de trabalho e a debilidade dos sistemas de seguridade social, que dificulta a inserção de indivíduos e grupos nas estruturas sociais e econômicas, levando-os a situação de vulnerabilidade social que se refere ao impacto resultante da configuração de estruturas e instituições socioeconômicas sobre comunidades, famílias e pessoas em distintas dimensões da vida social (Bellenzani e Malfitano, 20o6). Esses indivíduos e grupos encontram-se em uma zona de instabilidade, entre a integração e exclusão, que resulta na dificuldade de acesso às oportunidades sociais, econômicas e culturais providas pelo Estado, pelo mercado e pela sociedade, o que gera debilidades ou desvantagens para o desempenho e mobilidade sociais dos atores, bem como no aumento das situações de desproteção e insegurança, o que põe em relevo os problemas de exclusão e marginalidade (Gomes e Pereira, 2005; Gontijo e Medeiros, 2009).

Esse fato social é de extrema relevância na composição da pobreza nas sociedades capitalistas. A análise das condições histórico-estruturais que deram origem à população em situação de rua remonta o fenômeno da pauperização vivenciado por países da Europa Ocidental no período pré-industrial (Silva, 2009).

Em países do continente europeu esse fenômeno é compreendido como consequência imediata da degradação do mercado de emprego, da precarização das relações de trabalho, do desemprego. Este contexto implica no crescimento de segmentos sociais em uma condição de exclusão, a qual atinge não apenas pequenos grupos de pessoas, mas grupos sociais e populações que, ao sofrerem um processo de desqualificação para o mundo do trabalho, passam a viver à margem dos processos e não conseguem voltar às relações de trabalho formal. A degradação da integração com base nas relações de trabalho pode acarretar o declínio de formas de sociabilidade, reverter identidades, filiações, formas de coesão e solidariedade, criando manifestações que aparecem 
como fraturas e rupturas do vínculo social, levando essas populações a viverem em estado de exclusão dos processos sociais e quebra das redes sociais de suporte (Castells, 2001).

A compreensão da realidade da pessoa em situação de rua remete a questões de ordem social, econômica e política decorrente de uma orientação político-econômica globalizada, na qual há uma imposição da economia e da racionalidade do capital sobre as dimensões social e humana. As restrições das políticas sociais decorrentes da crise do Estado de bem-estar social e da necessidade do capital de assegurar a competitividade conduzem o Estado-nação, historicamente mediador e garantidor dos sistemas de proteção social, a perder sua potência frente aos grandes conglomerados capitalistas transnacionais, tendo os sistemas de proteção social sacrificados progressivamente por imperativos da nova natureza dos mercados (Domingues, 2005).

No Brasil, o fenômeno da população em situação de rua tem origem no processo de industrialização, que substituiu o modelo de acumulação agroexportadora, ocorrido no período de 1930 a 1980, que marcou definitivamente a economia e vida do país (Silva, 2009). Entretanto, têm sido apontadas causas estruturais históricas para situações de extrema pobreza, que remontam à organização política, econômica e cultural historicamente produzida na sociedade brasileira. Assim, a desigualdade social, econômica e política tem marcado a constituição histórica do país e se tornado incompatível com a democratização da sociedade. Em decorrência fala-se em uma "apartação social”, uma lógica que está presente nas várias formas de relações econômicas, sociais, culturais e políticas e que leva a uma situação de privação coletiva que inclui pobreza, subalternidade, iniquidade, não acessibilidade e não representação pública (Varanda e Adorno, 2004; Holston, 2013).

O estudo de abrangência nacional "Pesquisa nacional sobre a população em situação de rua”, realizado em 2008, quantificou e caracterizou socioeconomicamente a população em situação de rua com o intuito de orientar a elaboração e implementação de políticas públicas. Essa pesquisa realizou um levantamento de campo censitário junto a 71 cidades brasileiras, identificando um contingente de 31.922 adultos vivendo em situação de rua nas cidades pesquisadas. Embora expressivo, esse número não representa o total da população vivendo nessa situação no país, uma vez que a pesquisa não envolveu a totalidade de municípios brasileiros (Brasil, 2008).

A pesquisa revela também dados que apontam o perfil dessa população, destacando-se que há predominância masculina ( $82 \%$ ) e que mais da metade (53\%) está em idade economicamente produtiva, entre 25 e 44 anos, apresentando como razões para viverem na rua problemas como uso de álcool e outras drogas (35,5\%), desemprego $(29,8 \%)$ e desavenças familiares (29,1\%). Tal população apresenta níveis de renda baixos, sendo que a maioria (52,6\%) recebe entre R\$20,oo e R\$ 8o,oo semanais. Dentre as atividades realizadas destacam-se: catador de materiais recicláveis $(27,5 \%)$, flanelinha $(14,1 \%)$, construção civil (6,3\%), limpeza (4,2\%) e carregador/ estivador (3,1\%); 15,7\% das pessoas entrevistadas relataram pedirem dinheiro como principal meio para a sobrevivência. Esses dados são importantes para desmistificar o fato de que a população em situação de rua é composta por "mendigos" e "pedintes", pois aqueles que pedem dinheiro para sobreviver constituem minoria (Brasil, 2008).

Ainda que pessoas em situação de rua possam integrar uma zona de assistência, formar uma rede social entre os pares na mesma condição e pessoas que oferecem ajuda ocasional, encontram-se em situação de flutuação na tessitura social e povoam seus interstícios sem encontrar um lugar designado e reconhecido. Encontram-se, frequentemente, em uma condição de não acessibilidade a uma vida digna, vivendo com base em pobreza extrema, destituídas de direitos, de estruturas básicas de sobrevivência, expostas a contextos de violência e imersas em uma condição de invisibilidade, sem reconhecimento social e representação pública (Varanda e Adorno, 2004). Nesse sentido, essa situação caracteriza-se como sendo de exclusão social, não entendendo essa exclusão de um ponto de vista normativo, derivada de incapacidades de desenvolvimento de condutas adaptativas, mas concebendo-a por meio da ótica da falta de acessibilidade aos bens materiais e imateriais produzidos pela sociedade, assim como de sua submissão a uma condição existencial marcada por iniquidades e injustiças sociais (Bottega e Merlo, 2010; Botti e col., 2010). 
A problemática da pessoa em situação de rua, em decorrência de sua complexidade, demanda a atuação de diferentes áreas do conhecimento e práticas de forma articulada, constituindo-se em uma rede de ações complementares e contínuas, visando o enfrentamento das questões que acometem essa população, envolvendo, assim, os setores da saúde, educação, assistência social e direito, entre outros. As políticas públicas mostram-se fragmentadas, insuficientes e setorizadas, demandando a organização interconectada de diversos setores e instâncias sociais no intuito de subsidiar a criação e articulação de políticas públicas que promovam a diminuição das desigualdades sociais, a discriminação e o estigma e criem estratégias de enfrentamento da problemática da exclusão social de populações e segmentos sociais (Lopes e col., 2008; Ferreira, 2011).

Dessa forma, no intuito de discutir o fenômeno e as problemáticas em torno da população em situação de rua, o curso de terapia ocupacional da Faculdade de Medicina de Ribeirão Preto da Universidade de São Paulo (TO - FMRPUSP) coordenou a realização do "I Encontro Saúde Ocupação e Contextos Psicossociais: populações em vulnerabilidade, intersetorialidade e cidadania”. O objetivo foi criar estratégias que envolvessem diversos setores da sociedade civil e da esfera governamental local para elaboração de políticas sociais resolutivas voltadas a segmentos sociais em extrema pobreza e em situação de rua.

0 encontro foi realizado nos dias 9 e 10 de agosto de 2012, sob a coordenação do Grupo de Pesquisa Saúde, Ocupação e Contextos Psicossociais, integrado por terapeutas ocupacionais e visando articular diversos setores sociais na discussão e elaboração de estratégias de promoção, inclusão social e criação de dispositivos de autodeterminação e autonomia voltados para essa população.

O evento mobilizou os seguintes setores da sociedade: secretaria municipais da Saúde, da Assistência Social, da Educação e da Cultura e organizações não governamentais que desenvolvem trabalho assistencial com moradores de rua. Foram realizados três grupos de trabalho, uma conferência e duas mesas redondas.

Os objetivos centrais que permearam a iniciativa do grupo na organização desse encontro foram dis- cutir as múltiplas causalidades e a complexidade envolvida com o fenômeno do crescimento da população em situação de rua na conjuntura geral do país e do mundo e no contexto do município; iniciar uma análise e caracterização social dessa população; e elaborar estratégias para elaboração de políticas públicas de inclusão social, redução de iniquidades e desigualdades e erradicação da pobreza no município de Ribeirão Preto, na interface com as dimensões de atuação, recursos e responsabilidades de vários setores da administração pública municipal (saúde, educação, cultura, habitação, transportes e meio ambiente, entre outros), além de organizações da sociedade civil.

As estratégias utilizadas no evento foram a realização de palestras expositivas sobre a população em situação de rua, com a participação de profissionais com experiência nesse contexto, no intuito de resgatar a problemática junto aos participantes do evento. Para a mobilização e articulação destes utilizou-se como recurso os grupos de trabalho, no intuito de favorecer as discussões e a elaboração de estratégias de enfrentamento das questões vivenciadas pela população em situação de rua.

Este artigo discorre sobre a experiência da realização do referido evento como estratégia de mobilização dos diversos atores do município, por meio dos grupos de trabalho (GT), para discussão da problemática da população em situação de rua, identificação dos diversos atores e setores envolvidos, bem como para articular as ações realizadas junto a essa população, promovendo uma atenção intersetorial e efetiva das pessoas em situação de rua.

A seguir será apresentado um eixo que discute a atuação da terapia ocupacional social, seguido dos eixos norteadores do encontro.

\section{A terapia ocupacional, o campo social e as pessoas em situação de rua}

O debate sobre a exclusão de grandes massas humanas também integra o campo de conhecimento e prática da terapia ocupacional (TO), tradicionalmente constituída como profissão inserida nas ciências da saúde, que, a partir da década de 1980, 
vem construindo sua atuação para além dos muros das instituições, direcionando sua intervenção para populações anteriormente não atendidas pela profissão, como moradores de rua, pessoas em presídios, crianças em abrigos, objetivando a construção de novas possibilidades de existência, a efetivação e garantia de direitos a bens e serviços disponíveis na sociedade (Soares, 2007).

No Brasil, o desenvolvimento de ações junto a populações em situação de vulnerabilidade social tem como marco o período nacional desenvolvimentista conhecido como "milagre econômico". Nesse período, em pleno regime ditatorial, os militares e conservadores, ao mesmo tempo em que promoveram a supressão da liberdade política, de expressão e de organização da população brasileira e a implantação de política econômica inflacionária e de arrocho salarial, propuseram algumas soluções que visavam trabalhar com a população excluída por meio de abordagens de inclusões perversas e outras de caráter psicopedagógicas e disciplinarizadoras. Estas englobaram desde as propostas habitacionais (via Sistema Financeiro de Habitação, Banco Nacional de Habitação - BNH) até a criação da instituição Fundação do Bem-Estar do Menor (Febem). Nesse contexto, muitos profissionais do campo da saúde, da pedagogia e da psicologia passaram a integrar programas voltados à população em vulnerabilidade social com base em uma atuação cuja finalidade era a ressocialização daqueles que se encontravam às margens do processo social (Soares, 2007).

Em meados dos anos 1970, imperava a análise estrutural-funcionalista para as questões sociais relacionadas à pobreza, que, ao disseminar uma visão de sociedade como uma estrutura consensual, inseriu a noção de marginalidade social para aqueles considerados os inadaptados ao sistema social. A teoria da marginalização social, na qual a política do bem-estar do menor se baseava, era definida a partir dessa concepção estrutural-funcionalista, que se constituiu como um dos principais referenciais teóricos utilizados na América Latina para explicar o conjunto das situações relacionadas à pobreza urbana. Nessa perspectiva, a marginalidade se dá pela não adaptação do elemento ao sistema. Assim, para manter a ordem social integrada, os problemas de não integração foram considerados como características daquele que não se integra e não relacionados à organização sociopolítica e econômica da sociedade da qual fazem parte. Na concepção estrutural-funcionalista os sujeitos que não se adaptam ao sistema são classificados como portadores de uma conduta desajustada, inadaptada e, dessa forma, a não integração da pessoa, entendida sob o âmbito individual, é tratada como um problema clínico, uma disfunção individual que precisa ser tratada. Esse referencial favorece o fenômeno da medicalização e psicologização dos conflitos sociais, ocultando os âmbitos político, econômico e social na geração da pobreza no país (Barros e col., 2007).

É nesse cenário que a terapia ocupacional inicia sua atuação social em presídios, nas instituições de recolhimento de menores e nos programas comunitários. 0 ingresso da profissão no campo social, portanto, ocorre sob a ditadura militar e sua atuação reflete a lógica das instituições totais e as políticas públicas de inserção perversa dessas populações (Barros e col., 2007). A atuação dos profissionais terapeutas ocupacionais, a partir dos anos 1980, passou por severas críticas internas, que reorientaram o contexto teórico-prático da profissão, surgindo novos caminhos, espaços de atuação e perspectivas de intervenção profissional, tais como a atenção primária à saúde e no Sistema Único de Saúde (SUS), nos serviços extra-hospitalares de saúde mental e na saúde coletiva (Drummond, 2007). Nesse contexto também surge uma terapia ocupacional no campo social que se pretende atuante junto às populações excluídas, mas sob um referencial que contribui para o debate a respeito de uma nova configuração da questão social, que emerge das contradições de sociedades marcadas pelas desigualdades que geram populações que vivem a precariedade das relações de trabalho e dissolução dos vínculos sociais. A atuação profissional orienta-se pelo referencial da busca de recursos que visem à emancipação civil e política desses grupos (Lopes e col., 2011).

Surge, portanto, uma terapia ocupacional social com o objetivo de transformar essa atuação e construir metodologias e tecnologias para trabalhar junto a pessoas em situação de vulnerabilidade, de forma a buscar a criação e o fortalecimento de 
redes sociais de suporte, emancipação e autonomia político-social dessas populações. Inicia-se, desse modo, a constituição de uma metodologia para a construção de projetos sociais e coordenação da ação de grupos e comunidades na busca de suas reivindicações, assim como a organização de setores da sociedade civil e da administração para elaboração, implantação e gestão das políticas públicas, fundamentando a ação do terapeuta ocupacional na prática social como articulador, tanto na esfera comunitária, no território, como nas esferas supraestruturais dos fóruns técnicos e populares, para elaboração e implementação de políticas sociais. Da mesma forma, no campo epistemológico inicia-se a construção referencial teórico que possa contribuir para uma análise do campo social que atrele e que se realize na interface entre cultura, sociedade e a dimensão pessoal (Almeida e col., 2011).

Assim, a terapia ocupacional social insere-se em uma base de atuação construída nos contextos das comunidades vulneráveis, urbanas e rurais, povos indígenas, vítimas de catástrofes naturais, vítimas de violência e população em situação de rua, entre outros (Lopes e col., 2011).

Um marco para a atuação da TO junto a essa população é a Resolução 17 do Conselho Nacional de Assistência Social - CNAS (Brasil, 2011), que reconheceu entre as categorias profissionais que atendem aos requisitos para o trabalho socioassistencial a terapia ocupacional, que passou a integrar o Sistema Único de Assistência Social (SUA) (Almeida e col., 2012). Sob esse prisma, terapeutas ocupacionais no campo social têm realizado estudos e desenvolvido intervenções abrangendo pessoas em situação de rua (Almeida e col., 2011; Ghirardi e col., 2005; Lopes e col., 2008; Malfitano e Marques, 2011).

No município de Ribeirão Preto (SP) o curso de graduação em terapia ocupacional da Faculdade de Medicina da Universidade de São Paulo (TO-FMRPUSP) iniciou suas ações junto à população em situação de rua em 2011, em parceria com o Centro de Referência Especializado da Assistência Social para a População em Situação de Rua (CREAS-POP), por meio de atividades de ensino, pesquisa e extensão.

O CREAS-POP é uma organização ligada à Secretaria Municipal de Assistência Social de Ribeirão
Preto, cuja finalidade é intervir junto a pessoas em situação de rua, oferecendo a elas assistência diurna diária, funcionando em rede com outros serviços de assistência social do município, governamentais ou não, visando o fortalecimento de vínculos e a sua reinserção na sociedade (Prefeitura Municipal de Ribeirão Preto, 2011). O serviço busca atender às diretrizes da Política Nacional de Assistência Social, integrando os serviços do Sistema Único de Assistência Social (SUAS), recomendado aos municípios com mais de 250.0oo habitantes (Brasil, 2010).

Os CREAS-POP tiveram origem a partir da Lei $11.258 / 2005$, que altera a redação do artigo $23^{\circ}$ da Lei Orgânica da Assistência Social - Lei 8742/1993, que contempla, através dos serviços de assistência social e da integração de uma rede de serviços organizados no SUAS, a criação de programas de amparo às pessoas que vivem em situação de rua. Com base nas diretrizes da política nacional e em razão do anúncio, pelo governo federal, em 2010, do Plano Integrado de Enfrentamento ao Crack e Outras Drogas, os serviços do Sistema Único de Assistência Social deram início à criação dos CREAS-POP em municípios com mais de 250.000 habitantes. Em Ribeirão Preto, a Secretaria Municipal de Assistência Social, de acordo com as diretrizes do Ministério do Desenvolvimento Social viabilizou o CREAS-POP a partir de 2011.

O centro de referência de Ribeirão Preto funciona desde 2011 como uma casa-dia, de caráter assistencial, oferecendo alimentação, higiene, vestimenta e assistência social e jurídica a pessoas em situação de rua. Mantém um convênio com a Secretaria Municipal de Saúde, especificamente com o Centro de Atenção Psicossocial em Álcool e Outras Drogas (CAPS-ad), com vistas a potencializar o acesso dos usuários de álcool e drogas em situação de rua ao tratamento disponibilizado.

Embora exista uma política que subsidie as ações junto à população em situação de rua, observa-se a necessidade de uma maior articulação entre os diversos atores e setores envolvidos nesta atenção, no intuito de articular estratégias em busca de ações efetivas que possibilitem o resgate da cidadania e a inserção social das populações em vulnerabilidade social. 
Intersetorialidade como estratégia para a articulação e multiplicação de recursos para a resolubilidade das questões sociais

Na perspectiva ampliada da discussão sobre intersetorialidade, tema central do evento, sabe-se que não há uma definição acabada, tampouco uma concepção única, pois ela ainda se encontra em construção enquanto conceito. Entendida como uma forma de gestão das políticas públicas, a intersetorialidade apresenta-se, na contemporaneidade, como uma necessidade histórica frente às questões socioculturais de grande complexidade, polissêmicas e multifacetadas que surgem nesta etapa histórica humana (Castells, 2011).

A lógica de uma interação de mútuo entendimento intersetorial a respeito de um ou mais projetos ou questões sociais apresenta-se como alternativa a uma anacrônica lógica setorial, fragmentada, vertical e autônoma em relação a outros setores, que vão reproduzindo, cada um em sua esfera de atuação, suas ações mais ou menos independentes umas das outras (Junqueira, 2004; Costa e Lionço, 2006).

Nos contextos atuais dos grandes centros urbanos, fundadores de uma multiplicidade cultural e de uma multidimensionalidade de modos de vida, os problemas sociais avolumaram-se e se complexificaram, adquirindo facetas globais e atingindo as formas mais tradicionais de coesão social e de gestão de populações por parte dos governos, dos diferentes Estados. A partir da reorientação neoliberal das políticas econômicas, presente na maioria dos Estados ocidentais, geradora da crise que envolve os sistemas de solidariedade social e da impotência dos Estados nacionais em gerirem as políticas sociais, aponta-se para a necessidade de ampliar a capacidade de enfrentamento de tais problemáticas, no sentido de garantir às populações os direitos de cidadania, que englobam vários segmentos da sociedade civil e das administrações públicas, no intuito de potencializar a construção de canais de exercício democrático (Sorj e Martuccelli, 2008).

A intersetorialidade, entendida como processos organizados e coletivos e ações deliberadas que pressupõem o respeito à diversidade e às parti- cularidades dos atores envolvidos, baseia-se na interação entre os diferentes segmentos e setores administrativos e da sociedade civil, com vistas a criar estratégias consensuais de ação social e interferindo na produção social e subjetiva ao produzir efeitos sobre os modos de ser e de atuar dos atores sociais, usuários e gestores de serviços e organizações (Sposati, 2006; Nascimento, 2010).

A importância da formação de instâncias intersetoriais para elaboração e deliberação de políticas e programas refere-se ao alcance e potencialização das intervenções, mostrando-se como um mecanismo de inovação e fortalecimento da gestão pública em face de problemáticas complexas, tais como: combate à pobreza, redução das desigualdades sociais e programas de transferência condicionada de renda nos Estados e municípios, exigindo a articulação de várias áreas da política social como educação, assistência social, trabalho etc. (Magalhães e col., 2011).

Outro aspecto relevante refere-se ao potencial da intersetorialidade de revitalizar as políticas públicas, mesmo quando se evidenciam alguns problemas na sua implementação, relacionados ao despreparo político e técnico dos gestores e dos profissionais para assumir a perspectiva intersetorial, ao não conseguirem se desvencilhar de questões administrativas que se impõem como entraves à articulação das ações. Entretanto, a partir da superação desses problemas, a intersetorialidade mostra-se como dispositivo potente de se trabalhar, governar e construir políticas públicas. Em uma perspectiva de superação das fragmentações de conhecimentos e estruturas sociais, as políticas públicas produzem efeitos significativos na integração de ações para responderem a determinadas problemáticas (Azevedo e col., 2012).

Entretanto, há uma série de dificuldades relacionadas às formações intersetoriais como estratégia de elaboração de políticas e programas. Há uma cultura de fragmentação nas formas de gestão da máquina pública no país que impede o desenvolvimento de estratégias compartilhadas, principalmente no que diz respeito aos recursos de financiamento das políticas públicas (Sposati, 2006). Além da lógica de fragmentação, há uma tendência cultural na sociedade contemporânea em 
apresentar propostas de resoluções de problemas sociais apenas apoiadas em uma racionalidade instrumental e técnica em detrimento de uma racionalidade comunicativa, na base da formação de fóruns democráticos para discussão e formação de consensos geradores de projetos para a ação social (Fiorati, 2012).

Esse aspecto cultural é importante porque pode contaminar os fóruns de discussão intersetorial, gerando um processo comunicativo permeado e atravessado por poderes de setores com interesses particulares e não coletivos, levando ao que Habermas (1994) chama de "comunicações sistematicamente distorcidas" no processo de formação de consensos fundados para a coordenação das ações sociais. Isso acontece quando uma instância formadora de consensos (por exemplo, um fórum intersetorial) é perturbada por interesses, poderes e enganos. Nesses casos um falso consenso se instaura, pois o diálogo foi corrompido e deixou de existir naquele processo comunicativo, que, ao mesmo tempo, deixa de dirigir-se para o entendimento mútuo para orientar-se por interesses privados e não públicos.

Assim, destaca-se o valor da dialogicidade na intersetorialidade. Ou seja, não basta uma superposição de olhares interdisciplinares, é preciso um diálogo resultante de uma interface recíproca permanente. Nesse aspecto, a proposição de consensos fundados de Habermas (1988) é coincidente, já que para haver uma verdadeira construção coletiva e coordenada para uma ação social é necessária uma autêntica simetria dialógica e intersubjetiva. Daí a necessidade da inclusão da sociedade civil, além dos órgãos públicos ou privados, na intersetorialidade (Mendes, 2011).

Nesse sentido, a criação de fóruns intersetoriais mostra-se como uma das formas de gestão de problemas sociais e de elaboração de políticas públicas que respondem a tais problemáticas. Portanto, com o intuito de apontar caminhos de resolubilidade à problemática de populações em extrema pobreza e pessoas em situação de rua, a intersetorialidade constituiu-se na principal proposição do evento para setores atuantes da administração pública e da sociedade civil a populações em vulnerabilidade social no município de Ribeirão Preto. Assim, além de perceber-se que a complexidade da problemática em torno das pessoas em situação de rua transcendem as barreiras da capacidade de resolução dos setores isoladamente, também se observa que há um isolamento na gestão de políticas públicas e a presença de uma impermeabilidade entre atores de diferentes setores.

Nesse sentido, as principais propostas trabalhadas no evento abrangeram a integração, interação, sinergia e comunicação entre os setores envolvidos para elaboração e implementação de políticas públicas integradas e resolutivas. Outro tema importante trabalhado pelo evento, e ligado à discussão sobre a intersetorialidade, foi a articulação em redes de atenção a pessoas e grupos em vulnerabilidade social.

Segundo Castells (2011), as redes são novas formas de organização social, do Estado ou da sociedade, intensivas em tecnologia de informação e baseadas na cooperação entre unidades dotadas de autonomia. Diferentes conceitos coincidem em elementos comuns das redes: relações relativamente estáveis, autonomia, inexistência de hierarquia, compartilhamento de objetivos comuns, cooperação, confiança, interdependência e intercâmbio constante e duradouro de recursos.

No suporte às políticas públicas, as têm sido propostas a partir da década de 1990 com vistas à superação do modelo burocrático, hierárquico e hegemônico em um contexto de globalização econômica e cultural, de intensa informatização e transmissão do conhecimento, de proliferação de organizações não governamentais e de fortalecimento do controle público (Sorj e Martuccelli, 2008).

Dessa forma, as redes têm sido apresentadas como alternativa para a administração de políticas públicas, em que há necessidade de gestão de recursos diante de problemas complexos. Na articulação em redes há interação de agentes públicos e privados, locais, regionais e federais, mostrando-se adequada onde há uma forte demanda por participação cidadã.

Nesse sentido, Mendes (2011) define redes de atenção como organizações poliárquicas de conjuntos de serviços, organizações e agentes, vinculados entre si por uma missão única, por objetivos comuns e por uma ação cooperativa e interdependente. Elas permitem ofertar uma atenção contínua e integral 
à determinada população, sendo coordenada por determinações consensuais, as quais orientam a ação prestada no tempo certo, no lugar certo, com o custo certo, com a qualidade certa, de forma humanizada e com equidade - e com responsabilidade econômica e geração de valor para a população.

Dessa forma, a proposta final do evento de uma articulação entre intersetorialidade e redes de atenção torna-se uma oportunidade única e muito relevante para elaboração, organização e gestão de políticas públicas direcionadas para a problemática complexa das populações em extrema pobreza e vulnerabilidade social no município de Ribeirão Preto. Também se mostra consoante com as propostas mais democráticas que se apresentam no nosso momento histórico.

Assim, para mobilizar os diferentes atores sociais presentes no evento utilizou-se como estratégia os grupos de trabalho (GT), que favoreceram as discussões das temáticas pertinentes à população em situação de rua. 0 desenvolvimento e os desdobramentos dos GT serão abordados nos itens a seguir.

\section{Os grupos de trabalho: redes de atenção, políticas públicas $e$ estratégias de intervenção}

Foram propostos três grupos de trabalho, dentre os quais os participantes do evento foram distribuídos aleatoriamente, no intuito de que cada um fosse composto por uma diversidade de atores sociais e envolvidos com diversos setores. Os temas abordados nos GT foram: redes de atenção à pessoa em situação de rua, políticas assistenciais e dispositivos para a autodeterminação, políticas públicas e estratégias de intervenção.

Cada grupo de trabalho foi composto por dois facilitadores vinculados aos diferentes setores participantes do evento. As discussões tiveram duração de uma hora e as propostas debatidas foram registradas e apresentadas no evento aos demais grupos. As propostas de cada GT foram:

- GT 1 - Redes de atenção à pessoa em situação de rua: foram elaboradas propostas que abordaram a questão da carência de uma rede articulada na cidade para atenção à pessoa em situação de rua e em extrema pobreza. Nessa perspectiva, as propostas focalizaram a criação de uma rede para articulação de setores da administração pública, organizações não governamentais e clubes ou associações de serviços. Foram propostas ações integradas entre as áreas de saúde, educação, esporte, cultura, meio ambiente e jurídica envolvendo o poder executivo nas esferas municipal e estadual, além de clubes/associações, serviços.

- GT 2 -Políticas assistenciais e dispositivos para a autodeterminação: as propostas abordaram a criação de serviços para o acolhimento humanizado à pessoa em situação de rua (semelhante ao Programa Humaniza SUS); a criação de abrigos noturnos e de moradias temporárias ou de média/longa permanência; criação de programas para a promoção de capacitação profissional e atividades de geração de renda; a implantação de ações articuladas com o setor educacional, ampliando a alfabetização e educação de adultos para atender essa população; ações culturais e esportivas nos espaços urbanos; a criação e manutenção de serviços de atenção à população em situação de rua em locais de fácil acesso, tal como a região central da cidade; e acesso universal aos serviços públicos.

- GT 3 - Políticas públicas e estratégias de intervenção: a criação de espaços de elaboração de políticas públicas intersetoriais voltadas para a organização de estratégias de ação para erradicação da pobreza e promoção da inclusão social de pessoas e populações em situação de exclusão social e miséria econômica; o fortalecimento do CREAS-POP de Ribeirão Preto e das ações de inclusão social da Política Nacional do SUAS, que prevê a criação e regulamentação dos CREAS-POP nos municípios do país. Propôs-se também a constituição deste equipamento como articulador da rede de atenção a essa população, bem como a capacitação permanente dos trabalhadores sociais. Juntamente com o setor saúde, foi proposta a criação de equipes de atenção em redução de danos e consultórios de rua. Além disso, a implementação de um plano de ações intersetoriais de caráter preventivo em relação à situação de pobreza com a criação de ações edu- 
cativas e culturais voltadas à inclusão cultural, educacional e profissional, com ações territoriais e baseado na comunidade, bem como a criação de conferências municipais com o objetivo de organizar ações gerais voltadas à erradicação da pobreza no município.

\section{Resultados e ações compartilhadas a partir do encontro}

O evento promoveu a identificação dos diferentes atores envolvidos na atenção à população em situação de rua, bem como das ações desenvolvidas por cada um deles, aspecto que pode vir a favorece a articulação das ações voltadas para essa população.

No final dos GT, os participantes, em plenária, elegeram uma comissão formada por docentes, estudantes, profissionais das áreas social, da saúde e da cultura e representantes de movimentos sociais e de organizações não governamentais para se reunirem posteriormente e elaborarem um documento resumindo as questões e proposições trabalhadas nos nos grupos, com a proposta de entregá-lo a autoridades públicas do município (vereadores, candidatos a prefeito, promotores) e lideranças dos movimentos sociais.

O documento foi elaborado pela comissão dias após o evento e foi entregue às pessoas e grupos referidos no Fórum Social de Ribeirão Preto, realizado pelo Centro de Estudos em Saúde (Cebes - Núcleo RP), no qual se encontravam representantes dos setores citados. 0 documento também foi entregue à prefeita, em reunião intersetorial realizada no início de 2013, da qual participaram a polícia militar, o Ministério Público, a Promotoria Pública da Infância e Juventude do Fórum Municipal de Ribeirão Preto, representantes das secretarias municipais de Assistência Social e da Saúde, docentes do curso TO-FMRP-USP e alguns movimentos sociais.

O Grupo de Pesquisa Saúde, Ocupação e Contextos Psicossociais, organizador do "I Encontro Saúde Ocupação e Contextos Psicossociais: populações em vulnerabilidade, intersetorialidade e cidadania”, ficou incumbido de propor novos espaços de discussão das questões relacionadas a populações em situação de vulnerabilidade, no intuito de acompanhar e orientar as propostas definidas no evento.
É importante destacar que o referido grupo tem desenvolvido projetos de pesquisa e extensão junto à população em situação de rua, em parceria com setores vinculados à prefeitura de Ribeirão Preto, com vistas a possibilitar maior conhecimento da caracterização dessa população, de suas necessidades e de uma maior articulação dos diferentes setores na atenção a ela.

Em julho de 2013 foi finalizada uma pesquisa com pessoas em situação de rua em Ribeirão Preto, coordenada pelo Laboratório de Estudos e Extensão em Terapia Ocupacional Social e Comunidades COMMUNITAS, integrante do Grupo de Pesquisa Saúde, Ocupação e Contextos Psicossociais do curso TO-FMRP-USP. Também foi finalizado um documentário, intitulado ExcluSOS, produzido a partir dos depoimentos filmados de histórias de vida de pessoas em situação de rua. 0 documentário traz as histórias de vida e as percepções dos sujeitos sobre a realidade das ruas e tem por objetivo fomentar discussões com a sociedade, em parceria com o Sesc Ribeirão Preto, o Cine Clube Cauim e o ECEU - Centro Cultural da Pró-Reitoria de Cultura e Extensão da Universidade de São Paulo. As exibições do documentário são seguidas de rodas de conversa, com a presença de algumas pessoas em situação de rua que participaram do documentário e de outros convidados, discutindo essa condição e os caminhos para minimizar o sofrimento de viver nas ruas. 0 filme foi apresentado na tenda cultural Ortega y Gasset, em São Paulo, no dia 21 de maio de 2014, sendo debatido por pesquisadores da saúde coletiva.

E, por fim, está em processo a formação uma rede de atenção psicossocial, com a participação de profissionais das áreas da saúde, educação, assistência social e jurídica, cujo objetivo é refletir a construção de estratégias intersetoriais para atenção a pessoas em sofrimento psíquico, em uso de álcool e outras drogas e em vulnerabilidade social. A formação dessa rede tem se pautado no documento produzido durante o encontro aqui discutido e pelo documentário ExcluSOS.

\section{Considerações finais}

Compreende-se que o "I Encontro Saúde, Ocupação e Contextos Psicossociais: população em vulnerabilidade, intersetorialidade e cidadania" possibilitou 
espaços para que diversos setores sociais pudessem refletir e discutir a questão da população em situação de rua.

As reflexões aqui debatidas trazem em si a síntese de um acontecimento social. E, para além de algo concluído, compreendemos que está colocado o desafio da organização e da articulação de uma rede de atenção à população em situação de rua. Essa construção deve considerar a intersetorialidade, compreendendo a complexidade que o tema em questão requer e como algo multidimensional, o que exige de todos os atores um olhar ampliado, envolvendo o sujeito singular e o seu coletivo, bem como suas necessidades específicas e as questões do contexto.

Ressalta-se a reflexão crítica propiciada a partir do evento segundo a qual a problemática abordada não constitui apenas uma ação do setor da saúde, ainda que as consequências para as condições de saúde dessa população mostram-se extremamente alarmantes, tampouco somente da assistência social. O conjunto de problemas relacionado à situação de rua é um problema de todos os setores da sociedade, pois é de ordem política, econômica, cultural e social. Portanto, deve envolver todos esses setores no âmbito das construções de estratégias de resolubilidade.

Por fim, tem-se a expectativa de que as ações intersetoriais avancem as discussões aqui colocadas e, subsidiadas por elas, construam ações articuladas concretas visando políticas públicas condizentes com essa realidade.

\section{Contribuição dos autores}

Fiorati foi responsável pela pesquisa, revisão de literatura, elaboração do artigo, escrita e finalização. Carretta foi responsável pela pesquisa, elaboração, escrita e revisão do artigo. Panúncio-Pinto foi responsável pela revisão de literatura, elaboração, escrita e revisão final. Lobato foi responsável pela pesquisa, revisão de literatura, escrita. Kebbe foi responsável pela redação e revisão final do artigo.

\section{Referências}

ALMEIDA, M. C. et al. Terapia ocupacional

e pessoas em situação de rua: criando oportunidades e tensionando fronteiras. Cadernos de Terapia Ocupacional da UFSCar, São Carlos, v. 19, n. 3, p. 351-36o, 2011.

ALMEIDA, M. C. et al. Processos e práticas de formalização da terapia ocupacional na assistência social: alguns marcos e desafios. Cadernos de Terapia Ocupacional da UFSCar, São Carlos, v. 20, n. 1, p. 33-41, 2012.

AZEVEDO, E. et al. Práticas intersetoriais nas políticas públicas de promoção de saúde. Physis: Revista de Saúde Coletiva, Rio de Janeiro, v. 22, n. 4, p. 1333-1356, 2012.

BARROS, D. D.; LOPES, R. E.; GUALHEIGO, S. Terapia ocupacional na prática social. In: CAVALCANTI, A.; GALVÃO, C. (Org.). Terapia ocupacional: fundamentação \& prática. Rio de Janeiro: Guanabara Koogan, 2007. p. 347-352.

BELLENZANI, R.; MALFITANO, A. P. M. Juventude, vulnerabilidade social e exploração sexual: um olhar a partir da articulação entre saúde e direitos humanos. Saúde e Sociedade, São Paulo, v. 15, n. 3, p. 115-130, 2006.

BRASIL. Ministério do Desenvolvimento Social e Combate à Fome. Pesquisa nacional sobre população em situação de rua. Brasília, DF, 2008.

BRASIL. Presidência da República. Casa Civil. Subchefia para Assuntos Jurídicos. Decreto ${ }^{\circ}$ 7.179, de 20 de maio de 2010. Plano integrado de enfrentamento ao crack e outras drogas. Diário Oficial da União, Brasília, DF, 20 maio 2010. Disponível em: <http://presrepublica.jusbrasil. com.br/legislacao/823082/decreto-7179-10>. Acesso em: 16 set. 2014. 
BRASIL. Ministério do Desenvolvimento Social e Combate à Fome. Resolução $n^{0} 17$, de 20 de junho de 2011. Ratificar a equipe de referência definida pela Norma Operacional Básica de Recursos Humanos do Sistema Único de Assistência Social - NOB-RH/SUAS e Reconhecer as categorias profissionais de nível superior para atender as especificidades dos serviços socioassistenciais e das funções essenciais de gestão do Sistema Único de Assistência Social - SUAS. Diário Oficial da República Federativa do Brasil, Brasília, DF, 21 jun. 2011. Seção 1.

BOTTEGA, C. G.; MERLO, A. R. C. Prazer e sofrimento no trabalho dos educadores sociais com adolescentes em situação de rua. Cadernos de Psicologia Social do Trabalho, São Paulo, v. 13, n. 2, p. 259-275, 2010.

BOTTI, N. C. L. et al. Prevalência de depressão entre homens adultos em situação de rua em Belo Horizonte. Jornal Brasileiro de Psiquiatria, Rio de Janeiro, v. 59, n. 1, p. 10-16, 2010.

CASTELLS, R. As metamorfoses da questão social: uma crônica do salário. 3. ed. Petrópolis: Vozes, 2001.

CASTELLS, M. A sociedade em rede: a era da informação: economia, sociedade e cultura. 6. ed. São Paulo: Paz e Terra, 2011.

COSTA, A. M.; LIONÇO, T. Democracia e gestão participativa: uma estratégia para a equidade em saúde? Saúde e Sociedade, São Paulo, v. 15, n. 2, p. 47-55, 2006.

DOMINGUES, L. H. Políticas sociais em mudança: o Estado, as empresas e a intervenção social. Lisboa: Instituto Superior de Ciências Sociais e Políticas, Universidade Técnica de Lisboa, 2005.

DRUMMOND, A. Fundamentos da terapia ocupacional. In: CAVALCANTI, A.; GALVÃO, C. (Org.). Terapia ocupacional: fundamentação \& prática. Rio de Janeiro: Guanabara Koogan, 2007. p. 10-17.

FERREIRA, F. P. M. Crianças e adolescentes em situação de rua e seus macro determinantes.

Saúde e Sociedade, São Paulo, v. 20, n. 2, p. 338-

349, 2011.
FIORATI, R. C. Projeto terapêutico nos serviços extra-hospitalares de saúde mental: uma reflexão crítica sobre a forma de elaboração e gestão dos projetos terapêuticos nos serviços. Saúde e Sociedade, São Paulo, v. 2, n. 3, p. 587-598, 2012.

GHIRARDI, M. I. G. et al. Vida na rua e cooperativismo: transitando pela produção de valores. Interface: Comunicação, Saúde, Educação, Botucatu, v. 9, n. 18, p. 601-610, 2005. Disponível em: <http://www.scielo.br/scielo.php? script=sci arttext\&pid=S1414-32832005000300014\&lng=en\& nrm=iso>. Acesso em: 14 jul. 2014.

GOMES, M. A.; PEREIRA, M. L. D. Família em situação de vulnerabilidade social: uma questão de políticas públicas. Ciência \& Saúde Coletiva, Rio de Janeiro, v. 10, n. 2, p. 357-363, 2005.

GONTIJO, D. T.; MEDEIROS, M. Crianças e adolescentes em situação de rua: contribuições para a compreensão dos processos de vulnerabilidade e desfiliação social. Ciência \& Saúde Coletiva, Rio de Janeiro, v. 14, n. 2, p. 467475, 2009.

HABERMAS, J. Teoría de la acción comunicativa. Madrid: Taurus, 1988.

HABERMAS, J. Teoría de la acción comunicativa: complemientos y estúdios prévios. Madrid: Ediciones Cátedra, 1994.

HOLSTON, J. Cidadania insurgente: disjunções da democracia e da modernidade no Brasil. São Paulo: Companhia das Letras, 2013.

JUNQUEIRA, L. A. P. A gestão intersetorial das políticas públicas e o terceiro setor. Saúde e Sociedade, São Paulo, v. 13, n. 1, p. 25-36, 2004.

LOPES, R. E. et al. Juventude pobre, violência e cidadania. Saúde e Sociedade, São Paulo, v. 17, n. 3 , p. 63-76, 2008.

LOPES, R. E.; BORBA, P. L. O.; CAPPELLARO, M. Acompanhamento individual e articulação de recursos em terapia ocupacional social: compartilhando uma experiência. O Mundo da Saúde, São Paulo, v. 35, n. 2, p. 33-238, 2011. 
MAGALHÃES, R. et al. Intersetorialidade, convergência e sustentabilidade: desafios do Programa Bolsa Família de Manguinhos- RJ. Ciência \& Saúde Coletiva, Rio de Janeiro, v. 16, n. 11, p. 4443-4453, 2011.

MALFITANO, A. S.; MARQUES, A. C. R. A entrevista como método de pesquisa com pessoas em situação de rua: questões de campo. Cadernos de Terapia Ocupacional da UFSCar, São Carlos, v. 19, n. 3, p. 289-296, 2011.

MENDES, E. V. As redes de atenção à saúde. Brasília, DF: OPAS, 2011.

NASCIMENTO, S. Reflexões sobre a intersetorialidade entre as políticas públicas. Serviço Social \& Sociedade, São Paulo, n. 101, p. 95-120, jan. 2010.

PREFEITURA MUNICIPAL DE RIBEIRÃO PRETO. Secretaria Municipal de Assistência Social. Departamento de Proteção Social Especial. Projeto do Centro de Referência Especializado de Assistência Social para Pessoas em Situação de Rua. Ribeirão Preto, 2011.
SILVA, M. L. L. Trabalho e população em situação de rua no Brasil. São Paulo: Cortez, 2009.

SOARES, L. B. T. A história da terapia ocupacional. In: CAVALCANTI, A.; GALVÃO, C. (Org.). Terapia ocupacional: fundamentação \& prática. Rio de Janeiro: Guanabara Koogan, 2007. p. 3-9.

SORJ, B.; MARTUCCELLI, D. O desafio latinoamericano: coesão social e democracia. Rio de Janeiro: Civilização Brasileira, 2008.

SPOSATI, A. Gestão pública intersetorial: sim ou não?: comentários de experiência. Serviço Social \& Sociedade, São Paulo, n. 85, p. 133-141, mar. 2006.

VARANDA, W.; ADORNO, R. C. F. Descartáveis urbanos: discutindo a complexidade da população de rua e o desafio para políticas de saúde. Saúde e Sociedade, São Paulo, v. 13, n. 1, p. 56-69, 2004.

Recebido: 29/03/2013

Reapresentado: 03/04/2014

Aprovado: 06/05/2014 